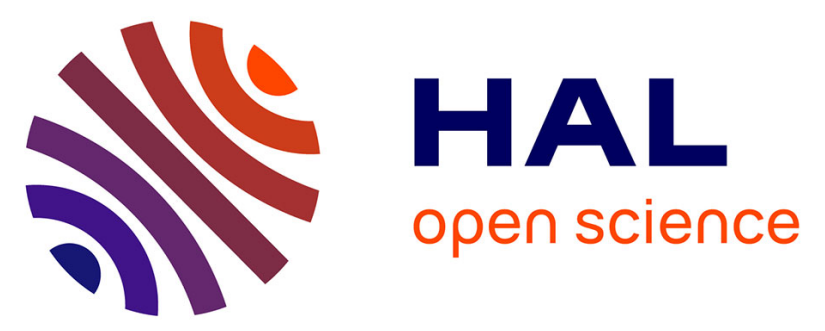

\title{
Modelling hydrodynamics of horizontal flow steel slag filters designed to upgrade phosphorus removal in small wastewater treatment plants
}

Cristian Barca, Stephane Troesch, Yves Andres, Florent Chazarenc, Nicolas Roche

\section{To cite this version:}

Cristian Barca, Stephane Troesch, Yves Andres, Florent Chazarenc, Nicolas Roche. Modelling hydrodynamics of horizontal flow steel slag filters designed to upgrade phosphorus removal in small wastewater treatment plants. Journal of Environmental Management, 2018, 206, pp.349-356. 10.1016/j.jenvman.2017.10.040 . hal-02111630

\section{HAL Id: hal-02111630 \\ https://hal-amu.archives-ouvertes.fr/hal-02111630}

Submitted on 26 Apr 2019

HAL is a multi-disciplinary open access archive for the deposit and dissemination of scientific research documents, whether they are published or not. The documents may come from teaching and research institutions in France or abroad, or from public or private research centers.
L'archive ouverte pluridisciplinaire HAL, est destinée au dépôt et à la diffusion de documents scientifiques de niveau recherche, publiés ou non, émanant des établissements d'enseignement et de recherche français ou étrangers, des laboratoires publics ou privés. 
archives-ouvertes

\title{
Modelling hydrodynamics of horizontal flow steel slag filters designed to upgrade phosphorus removal in small wastewater treatment plants
}

\author{
Cristian Barca, Nicolas Roche, Stephane Troesch, Yves Andres, Florent
}

Chazarenc

\section{To cite this version:}

Cristian Barca, Nicolas Roche, Stephane Troesch, Yves Andres, Florent Chazarenc. Modelling hydrodynamics of horizontal flow steel slag filters designed to upgrade phosphorus removal in small wastewater treatment plants. Journal of Environmental Management, Elsevier, 2018, 206, pp.349356. 10.1016/j.jenvman.2017.10.040 . hal-02111630

\section{HAL Id: hal-02111630 \\ https://hal-amu.archives-ouvertes.fr/hal-02111630}

Submitted on 26 Apr 2019

HAL is a multi-disciplinary open access archive for the deposit and dissemination of scientific research documents, whether they are published or not. The documents may come from teaching and research institutions in France or abroad, or from public or private research centers.
L'archive ouverte pluridisciplinaire HAL, est destinée au dépôt et à la diffusion de documents scientifiques de niveau recherche, publiés ou non, émanant des établissements d'enseignement et de recherche français ou étrangers, des laboratoires publics ou privés. 
Research article

\title{
Modelling hydrodynamics of horizontal flow steel slag filters designed to upgrade phosphorus removal in small wastewater treatment plants
}

\author{
Cristian Barca ${ }^{\text {a, }}$, Nicolas Roche ${ }^{a}$, Stéphane Troesch ${ }^{b}$, Yves Andrès ${ }^{c}$, Florent Chazarenc ${ }^{c}$ \\ a Aix-Marseille Univ., CNRS, Centrale Marseille, M2P2 UMR 7340, 13451, Marseille, France \\ ${ }^{\mathrm{b}}$ Epur Nature SAS, ZAC des Balarucs, 84510, Caumont sur Durance, France \\ ' IMT Atlantique, GEPEA UMR CNRS 6144, Université Bretagne Loire, 4 rue Alfred Kastler, F-44307, Nantes, cedex 03, France
}

\section{A R T I C L E I N F O}

Article history:

Received 2 May 2017

Received in revised form

26 September 2017

Accepted 19 October 2017

Available online 1 November 2017

Keywords:

Steel slag filters

Phosphorus removal

Hydrodynamic model

Multi-flow path model

Plug flow with dispersion

Tanks in series

\begin{abstract}
A B S T R A C T
Steel slag filters, if well designed and operated, may upgrade phosphorus removal in small wastewater treatment plants such as stabilization ponds and constructed wetlands. The main objective of this study was to develop a systemic modelling approach to describe changes in the hydraulic performances and internal hydrodynamics of steel slag filters under real dynamic operating conditions. The experimental retention time distribution curves (RTD curves) determined from tracer experiments performed at different times during the first year of operation of two field-scale steel slag filters were analyzed through a three stage process. First, a statistical analysis of the RTD curves was performed to determine statistical parameters of the retention time distribution. Second, classical tanks in series (TIS) and plug flow with dispersion (PFD) models were used to obtain a first evaluation of the dispersion and mixing regime. Finally, a multi-flow path TIS model, based on the assumption of several flow paths with different hydraulic properties, is proposed to accurately describe the internal hydrodynamics. Overall, the results of this study indicate that higher $\mathrm{CaO}$ content, round shape, and larger grain size distribution of steel slag may promote plug-like flow rather than dispersion. The results of the multi-flow path TIS model suggest that the internal hydrodynamics of steel slag filters can be primarily described by two main flow paths: (i) a faster main flow path showing higher plug flow, followed by (ii) a slower secondary flow path showing higher dispersion. The results also showed that internal hydrodynamics may change over time as a consequence of physical-chemical phenomena occurring in the filter, including accumulation of precipitates, slag hydration and carbonation, and particle segregation.
\end{abstract}

\section{Introduction}

Several studies have demonstrated that the addition of separate filter units containing steel slag as reactive material can upgrade phosphorus (P) removal in small wastewater treatment plants (WWTPs) such as stabilization ponds and constructed wetlands (CWs) (Vohla et al., 2011). The main mechanism of P removal is related to dissolution of $\mathrm{CaO}$ slag followed by precipitation of $\mathrm{Ca}-\mathrm{P}$ and the accumulation of Ca-P precipitates in the filters (ClaveauMallet et al., 2012; Barca et al., 2014). However, most of these experiments were performed at laboratory scale under controlled temperature conditions and using synthetic $P$ solutions, and only a few field-scale experiments have been conducted under real

\footnotetext{
* Corresponding author.

E-mail address: cristian.barca@univ-amu.fr (C. Barca).
}

operating conditions (Shilton et al., 2006; Lee et al., 2010; Barca et al., 2013). There is therefore a lack of data in the literature concerning the long term hydraulic and treatment performances of full-scale systems.

The hydraulic performances of filter units are usually evaluated by analyzing the experimental retention time distribution curves (RTD curves), which are often determined by measuring the tracer response at the outlet of the filters after impulse tracer injection at the filter inlet (Headley and Kadlec, 2007). Two classical hydrodynamic models are commonly used to describe the experimental RTD curves of real reactors: (i) the tanks in series model (TIS), which is based on the assumption of a series of $N$ continuously stirred tank reactors (CSTR) of the same volume, and (ii) the plug flow with axial dispersion model (PFD), which is based on the hypothesis of a simple convective plug flow affected by axial dispersion. Indeed, the use of the classical TIS and PFD models can provide a first evaluation of the dispersion and mixing regime in the filters 
(Chazarenc et al., 2003; Bonner et al., 2017).

However, several authors have shown that the classical TIS and PFD models often do not accurately accommodate high, early, multi-peaks, and long tails of experimental RTD curves (Werner and Kadlec, 2000; García et al., 2004), resulting in only rough estimation of the internal hydrodynamics of wastewater treatment filters. Moreover, it should be noted that numerous biological and physical-chemical phenomena, including biofilm growth, vegetation growth, inert accumulation, precipitation and accumulation of precipitates, and particle segregation can have a direct influence on changes in the porosity and pore size of the filters, thus affecting internal flow transport patterns and modifying internal hydrodynamics (Maloszewski et al., 2006; Suliman et al., 2006; Ríos et al., 2009; Samsó et al., 2016). In addition, most of these phenomena can be affected by changes in temperature and/or organic and inorganic loads (Muñoz et al., 2006; Rizzo et al., 2014). Consequently, there is a need to develop more complex dynamic models to better describe the changes in internal hydrodynamics under real operating conditions (Kumar and Zhao, 2011; Nivala et al., 2012; Meyer et al., 2015). A wide range of more complex models, including TIS with delay, TIS with exchange zones, multi-flow path PFD, and/or networks of TIS and PFD, have been proposed to describe the experimental RTD curves of wastewater treatment filters (Werner and Kadlec, 2000; García et al., 2004; Maloszewski et al., 2006; Zeng et al., 2013).

The main objective of this study was to develop a systemic modelling approach to describe changes in the hydraulic performances and internal hydrodynamics of steel slag filters under real operating conditions. Two field-scale steel slag filters, one filled with electric arc furnace slag (EAF filter), the other filled with basic oxygen furnace slag (BOF filter), were designed to treat the effluent of a CW. The design of the filters and the experimental results are detailed in Barca et al. (2013). Tracer experiments were conducted at different times during the first year of operation, and the experimental RTD curves were plotted. Filter hydrodynamics and P removal kinetics had already been modelled using a plug flow with dead volume model and a first order kinetic equation (Barca et al., 2013). In the present study, the experimental RTD curves were further examined in order to build a more complex dynamic model to describe the changes in the internal flow patterns.

A systemic modelling approach was used involving knowledge of chemical reactor engineering applied at three different scales of investigation. First, a statistical analysis of the experimental RTD curves was carried out to determine statistical parameters including the mean retention time, the variance of the distribution, and the hydraulic efficiency of the filters. Second, classical TIS and PFD models were used to obtain a preliminary evaluation of the dispersion and mixing regime, and to identify the type of model that best describes the experimental RTD curves. Finally, a multiflow path TIS model, based on the assumption of several flow paths with different hydraulic properties, was developed to describe changes in internal hydrodynamics and flow patterns.

The results of this study provide useful information to understand changes in the hydraulic performances of steel slag filters in real operation mode. Knowledge and understanding of hydraulic behavior under real operating conditions is indispensable to improve the design and operation of the filter system.

\section{Material and methods}

\subsection{Filter design and operation}

Two field-scale steel slag filters each with a total volume of $6 \mathrm{~m}^{3}$ (length $5.7 \mathrm{~m}$, width $2.1 \mathrm{~m}$, height $0.5 \mathrm{~m}$ ) were designed to upgrade $\mathrm{P}$ removal in a municipal wastewater treatment CW (La Motte
d'Aigues, France, 1050 people equivalent (p.e.), 150 L/(p.e. ${ }^{*}$ d)). One of the filters was filled with EAF slag (EAF filter), the other with BOF slag (BOF filter). Fig. S1 shows the grain size distribution of the steel slag used to fill the filters (supplementary material). The granular range $20-40 \mathrm{~mm}$ represented $96.8 \%$ and $77.9 \%$ of the total weight of EAF and BOF slag, respectively. The initial filter porosity of both filters was about 0.5 , thus resulting in an initial void volume of about $3 \mathrm{~m}^{3}$ for each filter.

The steel slag filters were fed with a fraction $(2-4 \%)$ of the effluent from the CW and operated according to a horizontal subsurface flow and batch loads (24 batches/day) to simulate typical CW-feed. During the first nine weeks of operation, the volume of each batch load was calibrated to $120 \mathrm{~L}$, thus leading to a theoretical hydraulic retention time based on the initial void volume (HRTv) of $24 \mathrm{~h}$. The HRTv was then increased to $48 \mathrm{~h}$ after nine weeks (week 9) of operation to evaluate the effect of HRTv on P removal. Further details on the design and operation of the filter, as well as the main results of $P$ removal performances, are given in a previous research paper (Barca et al., 2013).

\subsection{Tracer experiments}

Tracer experiments were performed in weeks 1 (Sept. 25-29, 2010), 9 (Nov. 22-25, 2010), 22 (Feb. 21-25, 2011), and 29 (Apr. 11-14, 2011) of operation to evaluate the hydraulic performances of the filters and changes over time. The HRTv was set to $24 \mathrm{~h}$ during each tracer test to compare the results of the different experiments. Five liters of a solution of $1 \mathrm{~g}$ fluorescein/L were instantaneously injected at the inlet of each filter ( $5 \mathrm{~g}$ fluorescein/filter). The concentrations of outlet tracer were then monitored until more than $90 \%$ of the mass of the tracer was recovered ( $48 \mathrm{~h}$ after injection of the tracer), and the concentrations of outlet tracer were plotted as a function of time.

\subsection{Statistical analysis of retention time distribution}

The hydraulic retention time distribution function $E(t)(1 / \mathrm{h})$ was obtained from the experimental results of the tracer experiments using equation (1), where $C(t)$ is the outlet tracer concentration $(\mathrm{g} /$ L) at time $\mathrm{t}(\mathrm{h})$.

$$
E(t)=\frac{C(t)}{\int C(t) \cdot d t}
$$

$E(t)$ is a probability density function that represents the fraction of water that has a retention time less than $t$ (Levenspiel, 1999). Next, the mean retention time $\tau(\mathrm{h})$, which represents the average time the water remains in the filter, was obtained by equation (2).

$\tau=\int t \cdot E(t) \cdot d t$

For each experiment, the variance of the retention time distribution $\sigma^{2}\left(\mathrm{~h}^{2}\right)$ was calculated by equation (3). $\sigma^{2}$ is an important parameter to assess the hydraulic performance of a filter, as it can be used as statistical indicator to evaluate the dispersive processes in the filter.

$\sigma^{2}=\int(t-\tau)^{2} \cdot E(t) \cdot d t$

The hydraulic efficiency parameter $\lambda(-)$ was calculated by equation (4), where $t_{p}$ is the peak tracer concentration time (h). Hydraulic efficiency $\lambda$ is usually used to evaluate both the effective volume utilization and the shape of the tracer response (García 
et al., 2004).

$\lambda=\frac{t_{P}}{\tau}$

According to Persson et al. (1999) hydraulic efficiency is good when $\lambda>0.75$, satisfactory when $0.5<\lambda \leq 0.75$, and poor when $\lambda \leq 0.5$.

\subsection{Classical TIS and PFD models}

The TIS and PFD models were used to describe the experimental $E(t)$ and to give a first estimation of the dispersion and mixing regime in the steel slag filters.

The TIS model is based in the assumption of a series of $N$ CSTRs of the same volume, where $N$ is defined as the number of TIS. The retention time distribution function $E(t)$ for the TIS model can be determined by analytical resolution of a system of $N$ equations of tracer mass balance, one equation for each CSTR. The behavior of a real reactor tends to the ideal plug flow reactor if $N$ tends to infinity. However, if $N$ is equal to 1 , the reactor is an ideal CSTR.

The PFD model is based on the hypothesis of a simple convective plug flow reactor in which the retention time distribution of the molecules of water is affected by the axial dispersion phenomenon. The dispersive flow conditions in real filters are usually evaluated by the dimensionless Péclet number $\mathrm{Pe}(-)$, as shown in equation (5), where $U$ is the actual flow speed $(\mathrm{m} / \mathrm{s}), l$ is the length of the filter $(\mathrm{m})$ and $D$ is the axial dispersion coefficient $\left(\mathrm{m}^{2} / \mathrm{s}\right)$.

$P e=\frac{U \cdot l}{D}$

As shown in equation (5), Pe increases with decreasing $D$. The behavior of a real reactor tends to the ideal plug flow reactor when $P e$ tends to infinity and $D$ tends to zero. In open boundary conditions, the retention time distribution function $E(t)$ for the PFD model can be determined analytically by equation (6), which shows the tracer mass balance for a generic infinitesimal section of reactor $\mathrm{dx}$.

$U \cdot \frac{\partial C}{\partial x}-D \cdot \frac{\partial^{2} C}{\partial x^{2}}+\frac{\partial C}{\partial x}=0$

In this study, retention time distribution functions $E(t)$ for the PFD and TIS models, as well as the optimum values for $P e$ and $N$, were determined by simulation and optimization of experimental $E(t)$ using the commercial software DTS-pro (PROGEPI, Nancy, France).

The Theil inequality coefficient (TIC) was used as a statistical indicator to evaluate the agreement between experimental and modelled $E(t)$. For each experiment, the TIC coefficient was calculated by equation ( 7 ), where $\mathrm{y}_{\mathrm{i}}$ and $\mathrm{y}_{\mathrm{m}, \mathrm{i}}$ represent experimental and modelled data, respectively.

TIC $=\frac{\sqrt{\sum_{i}\left(y_{i}-y_{m, i}\right)^{2}}}{\sqrt{\sum_{i} y_{i}^{2}}+\sqrt{\sum_{i} y_{m, i}^{2}}}$

A value of TIC below 0.3 usually indicates good agreement between experimental and modelled data (Hvala et al., 2005).

\section{Results and discussion}

\subsection{Statistical analysis of retention time distribution}

The experimental $E(t)$ for tracer experiments performed at different times during the operation of the EAF and BOF filters are shown in Fig. $1 \mathrm{a}$ and $\mathrm{b}$, respectively. With the exception of the EAF filter in week 29, the experimental $E(t)$ showed only one main peak ranging from 12 to $16 \mathrm{~h}$ and from 14 to $22 \mathrm{~h}$ after injection of tracer for the EAF and BOF filter, respectively.

The main results of the statistical analyses of retention time distribution are summarized in Table 1 . With the exception of the experiments performed in week 29, the EAF filter showed lower $\tau$ and higher $\sigma^{2}$ than the BOF filter. Overall, $\tau$ ranged from 16.8 to $23.4 \mathrm{~h}$ for the EAF and from 18.5 to $25.2 \mathrm{~h}$ for the BOF filter. These values of $\tau$ are close to the value of HRTv (24 h), thus suggesting good hydraulic efficiency of the filters. The $\sigma^{2}$ values ranged from 51.4 to $68.7 \mathrm{~h}^{2}$ and from 32.7 to $53.4 \mathrm{~h}^{2}$ for EAF and BOF filter, respectively. These results suggest a wider distribution of retention time for the EAF filter than for the BOF filter. In addition, the results in Table 1 show a clear tendency of $\sigma^{2}$ to decrease with decreasing air temperature in both the filters. Most probably, the higher water viscosity at lower temperature had the effect of limiting the dispersion phenomena, thus leading to shorter $\sigma^{2}$. The values of $\lambda$ ranged from 0.69 to 0.85 for the EAF filter and from 0.75 to 0.92 for the BOF filter (Table 1). Overall, these values confirm the good hydraulic efficiency of both the filters, although the BOF filter performed better than the EAF filter.

Statistical differences in the retention time distribution between the EAF and BOF filters were most probably related to the different shape and grain size distribution of the slag, as shown in Fig. S1. It is likely that the larger grain size distribution of the BOF slag resulted in a smaller pore size with smaller grains occupying the spaces between the larger grains. As a result, the smaller pore size in the BOF filter had the effect of reducing preferential paths, thus leading to lower $\sigma^{2}$ and higher $\lambda$, and keeping $\tau$ close to the value of the theoretical HRTv. In addition, the nearly round shape of the BOF slag may also have promoted a more uniform flow distribution, whereas the square shape of the EAF slag may have favored channeling, thus leading to less efficient use of the volume. The actual working volumes of the filters, based on the inlet flow and $\tau$, ranged from 2.09 to $2.81 \mathrm{~m}^{3}$ and from 2.22 to $3.28 \mathrm{~m}^{3}$ for EAF and BOF filter, respectively (Table 1 ). The actual working volume of the BOF filter decreased over time, probably related to a decrease in porosity due to accumulation of suspended solids and/or P precipitates during operation. Moreover, $\mathrm{CaO}$ slag hydration and/or carbonation during filter operation most probably increased the volume of the slag grains, thereby further reducing the void volume of the filter (Wang et al., 2010). Hence, the higher CaO slag content of the BOF slag (Barca et al., 2013) may account for the decrease in the actual working volume that was observed in the BOF filter. As can be seen in Fig. 1b, the left-to-right shift of the main tracer peak appears to further confirm the reduction in the porosity of the BOF filter over time. In contrast, the variation in the working volume in the EAF filter did not appear to be directly related to time, suggesting that more complex phenomena such as changes in preferential flow paths and/or particle segregation and/or channeling account for changes in the hydraulic behavior of EAF filter during its operation.

It should however be noted that the two filters showed no significant differences in $\mathrm{P}$ removal during the first 29 weeks of operation (Barca et al., 2013), thus indicating that the amounts of $P$ accumulated over time in the EAF and BOF filters were very similar and hence do not account for the differences in hydraulic behavior between the two filters.

\subsection{Classical TIS and PFD models}

The TIS and the PFD models were used to describe experimental $E(t)$ of EAF and BOF filters. The modelled $E(t)$ for the EAF and BOF filters are shown in Figs. 2 and 3, respectively, and the main TIS and 

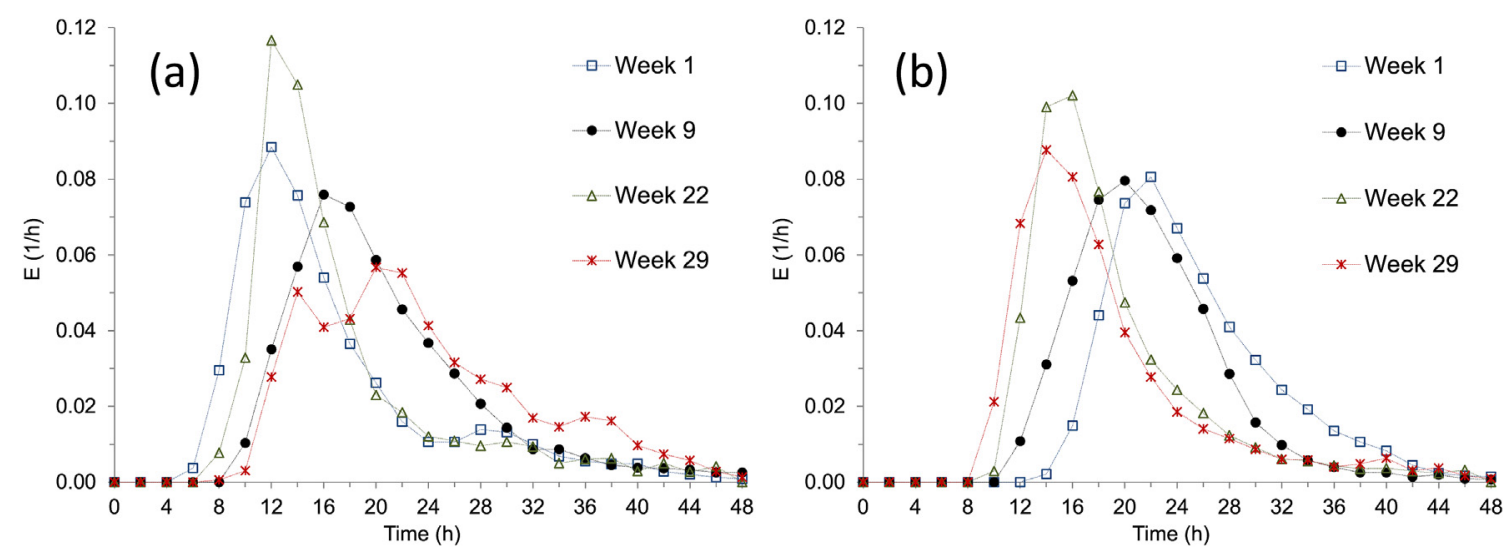

Fig. 1. Changes in experimental $E(t)$ for the EAF filter (a) and BOF filter (b) during their operation (experimental data, the dotted lines are there to facilitate interpretation).

Table 1

Main results of statistical analyses of retention time distribution.

\begin{tabular}{|c|c|c|c|c|c|c|c|}
\hline Week of operation & Average air temperature $\left({ }^{\circ} \mathrm{C}\right)$ & Filter & Mass recovery $(\%)$ & $\tau(\mathrm{h})$ & $\lambda(-)$ & $\sigma^{2}\left(h^{2}\right)$ & Actual working volume $\left(\mathrm{m}^{3}\right)$ \\
\hline \multirow[t]{2}{*}{1} & 13.3 & $\mathrm{EAF}$ & $>99$ & 16.8 & 0.71 & 64.2 & 2.18 \\
\hline & & BOF & 94.5 & 25.2 & 0.87 & 38.9 & 3.28 \\
\hline \multirow[t]{2}{*}{9} & 4.8 & EAF & 98.4 & 20.6 & 0.77 & 51.4 & 2.66 \\
\hline & & BOF & 98.9 & 21.8 & 0.92 & 32.7 & 2.83 \\
\hline \multirow[t]{2}{*}{22} & 11.6 & EAF & $>99$ & 17.4 & 0.69 & 60.8 & 2.09 \\
\hline & & BOF & $>99$ & 19.0 & 0.84 & 44.2 & 2.28 \\
\hline \multirow[t]{2}{*}{29} & 21.2 & EAF & $>99$ & 23.4 & 0.85 & 68.7 & 2.81 \\
\hline & & $\mathrm{BOF}$ & $>99$ & 18.5 & 0.75 & 53.4 & 2.22 \\
\hline
\end{tabular}
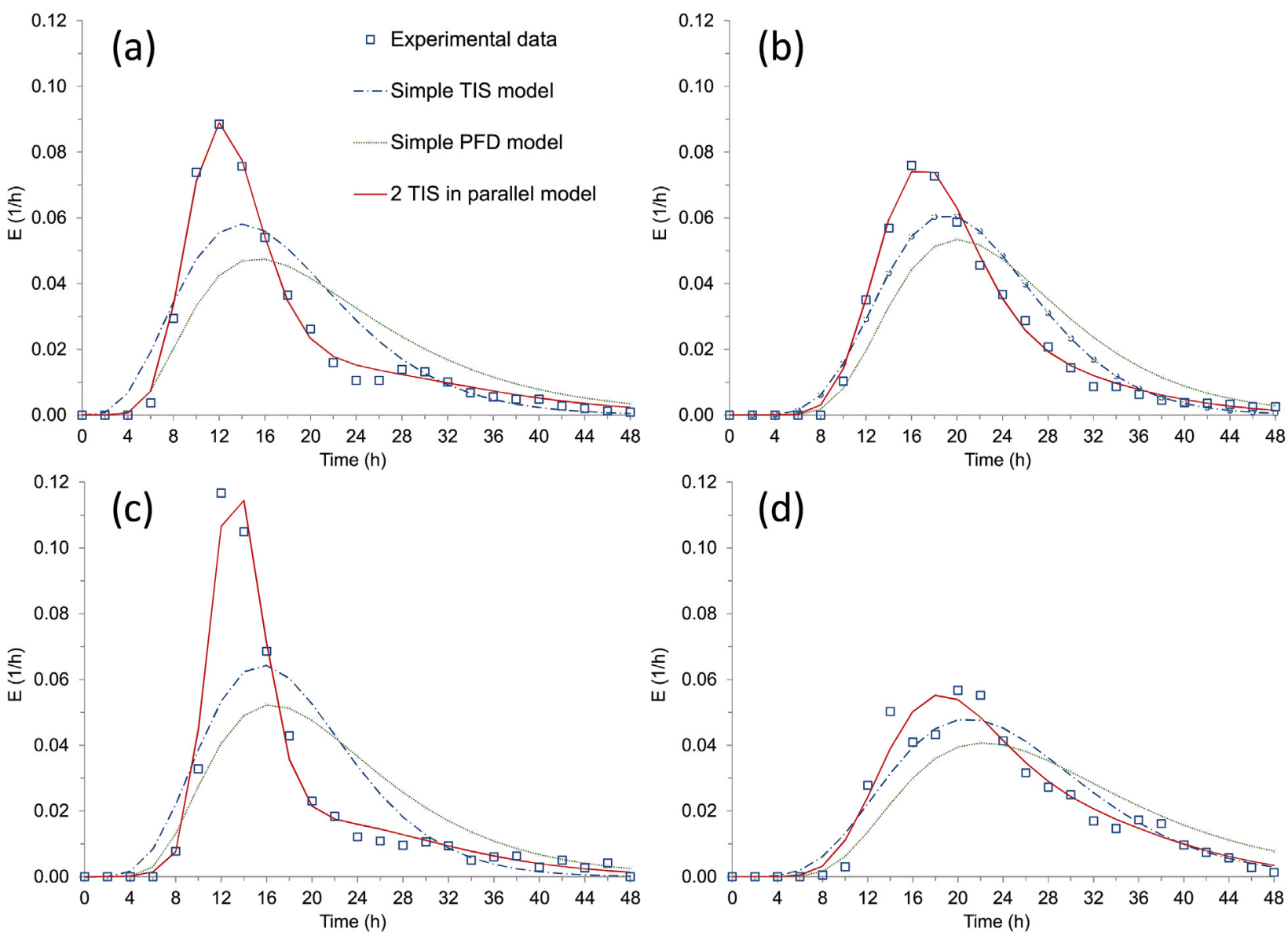

Fig. 2. Experimental and modelled $E(t)$ for the EAF filter: (a) week 1 of operation; (b) week 9; (c) week 22; (d) week 29. 

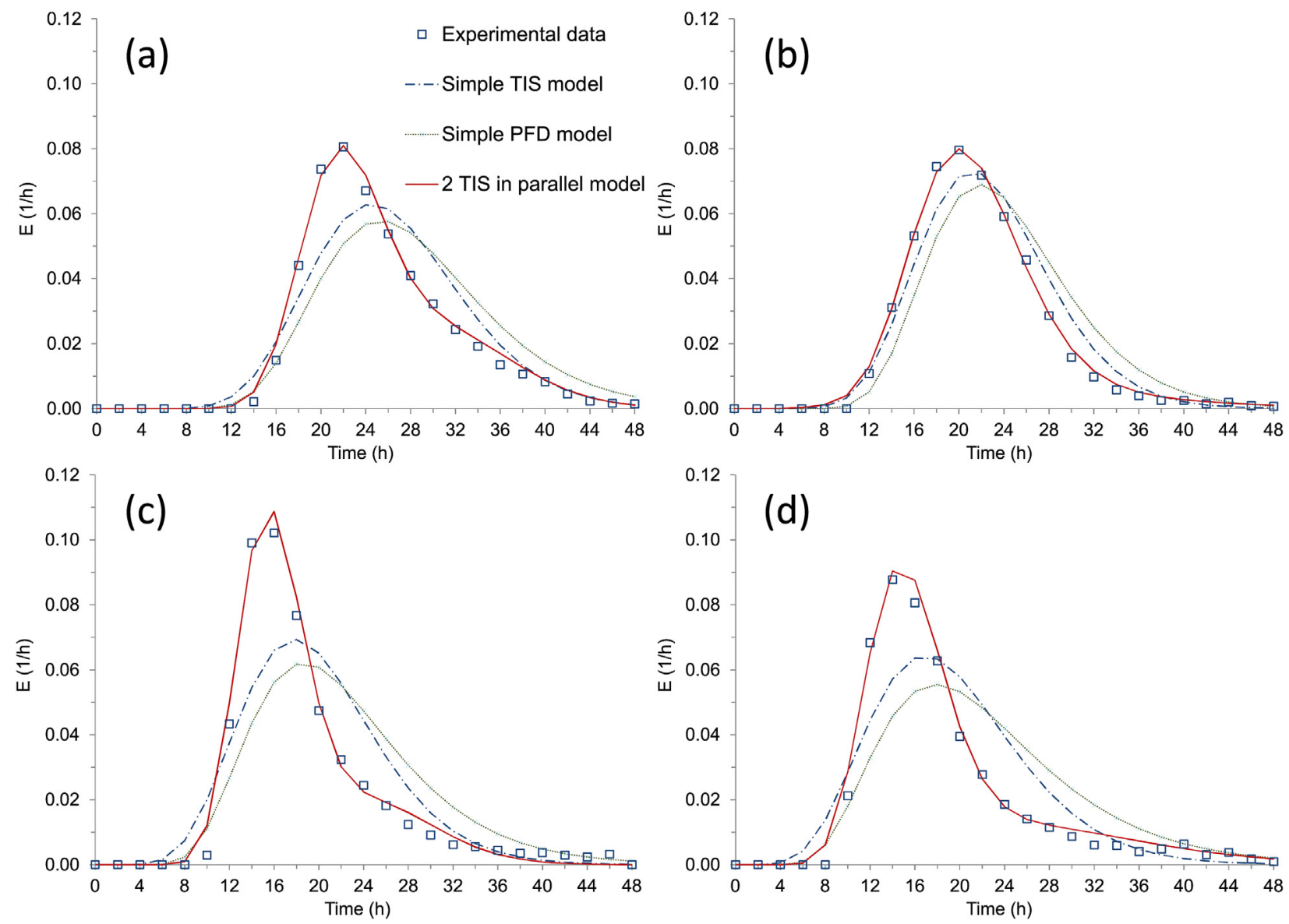

Fig. 3. Experimental and modelled $E(t)$ for BOF filter: (a) week 1 of operation; (b) week 9; (c) week 22; (d) week 29.

PFD model results are listed in Table 2.

When the TIS model was used, $N$ varied from 5 to 9 for the EAF filter and from 8 to 15 for the BOF filter (Table 2). When the PFD model was used, Pe varied from 7.53 to 14.7 for the EAF filter and from 12.8 to 27.8 for the BOF filter. Overall, these results suggest higher plug flow and lower dispersion in the BOF filter than in the EAF filter, which is consistent with the results of the statistical analyses of retention time distribution (Table 1). The results in Table 2 also show a clear tendency of Pe to increase with decreasing temperature. This confirms that the decrease in temperature accounts for the decrease in dispersion phenomena in the filters. Overall, TIC values indicate that the TIS model fits the experimental results better than the PFD model (Table 2). This is in good agreement with the results of previous studies showing that the TIS model represents the hydrodynamics of horizontal flow CWs more

Table 2

Main results of simple TIS and PFD models.

\begin{tabular}{|c|c|c|c|c|c|}
\hline \multirow[t]{2}{*}{ Week of operation } & \multirow[t]{2}{*}{ Filter } & \multicolumn{2}{|c|}{ TIS model } & \multicolumn{2}{|c|}{ PFD model } \\
\hline & & $\mathrm{N}$ & TIC & $\mathrm{Pe}$ & TIC \\
\hline \multirow[t]{2}{*}{1} & EAF & 5 & 0.195 & 7.53 & 0.281 \\
\hline & BOF & 15 & 0.148 & 26.3 & 0.198 \\
\hline \multirow[t]{2}{*}{9} & EAF & 9 & 0.129 & 14.7 & 0.203 \\
\hline & BOF & 15 & 0.087 & 27.8 & 0.153 \\
\hline \multirow[t]{2}{*}{22} & EAF & 7 & 0.276 & 9.96 & 0.342 \\
\hline & BOF & 10 & 0.216 & 17.0 & 0.274 \\
\hline \multirow[t]{2}{*}{29} & EAF & 7 & 0.118 & 10.9 & 0.186 \\
\hline & BOF & 8 & 0.194 & 12.8 & 0.261 \\
\hline
\end{tabular}

accurately than the PFD model (Chazarenc et al., 2003; García et al., 2004; Ríos et al., 2009).

\subsection{The multi-flow path TIS model}

The results in Figs. 2 and 3 suggest that classical TIS and PFD models do not accurately describe the high main peaks and the long tails of experimental $E(t)$, as already found in previous studies that investigated the hydraulic performances of horizontal flow CWs (Chazarenc et al., 2003; García et al., 2004). Several authors have proposed more complex models to improve the description of tracer response. García et al. (2004) proposed the use of the TIS with delay model to better assess the main peak of experimental $E(t)$. Maloszewski et al. (2006) proposed the use of a multi-flow dispersion model, which assumes the existence of several flow paths with different hydraulic properties.

In this study we investigated the use of a multi-flow path TIS model to improve the description of the experimental $E(t)$ and to better assess the internal hydrodynamics of the filters. Several reasons motivated the choice of this model. First, the results described in the previous section already demonstrated that the TIS model represents the hydrodynamics of steel slag filters more accurately than the PFD model. Moreover, the use of a multi-flow path TIS model can give a detailed and dynamic description of the main flow paths inside the filters. In addition, the multi-flow path TIS model is easy to understand for a non-expert user, and can easily be implemented in most software dedicated to the modelling and simulation of wastewater treatment processes. 


\subsubsection{Two flow path TIS model}

The two flow path TIS model is based on the assumption of two flow paths flowing in parallel into the filter: (i) a main flow path, which accounts for the main peak, and (ii) a secondary flow path, which accounts for the long tails of the experimental $E(t)$. The two flow paths were thus modelled according to a two TIS in parallel configuration, as shown in Fig. S2 (supplementary material). Each flow path is characterized by a specific volumetric flow rate, a mean retention time $\tau$, an actual working volume, and a number $N$ of TIS.

The input values for the specific volumetric rates of main and secondary flow paths were evaluated by graphical analysis of the experimental $E(t)$. The specific volumetric rate for the main flow path was estimated by the left-to-right symmetry of the main peak. The specific volumetric rate for the secondary flow path was then determined by flow balance at the inlet and at the outlet nodes, as shown in Fig. S2. The modelled $E(t)$ and the optimum values of $N$ for the two flow paths were determined by simulation and optimization of experimental $E(t)$ using the commercial software DTS-pro.

Figs. 2 and 3 suggest that the two flow path TIS model accurately describes the high main peaks and the long tails of experimental $E(t)$. The main results of the use of the two flow path TIS model are summarized in Table 3.

With the exception of the EAF filter in week 29, the results shown in Table 3 confirm that the internal hydrodynamics of the filters can be described by two major flow paths with different hydraulic properties:

(i) A faster main flow path showing lower $\tau$ and higher $N$ : under this hypothesis, this main flow path accounts for water flowing through the main central section of the filters, where a more uniform flow distribution promotes a plug-like flow regime;

(ii) A slower secondary flow path showing higher $\tau$ and lower $N$ : under this hypothesis, the secondary flow path is related to water flowing through nearly dead volumes or slow exchange zones (e.g. the bottom of the filters) where dispersion phenomena are more relevant than convective phenomena.

Overall, specific volumetric rates for the main flow path accounted for from $62 \%$ to $72 \%$ and from $71 \%$ to $84 \%$ of the total inlet flow for the EAF and BOF filters, respectively. The specific volumetric rates of the main flow path in both filters appear to increase with decreasing temperature, suggesting that higher water viscosity at lower temperature promotes one main flow path. With the exception of the experiments performed in week 29, the BOF filter showed higher specific volumetric rates and higher actual working volumes for the main flow path than the EAF filter. This is consistent with the higher plug flow and lower dispersion conditions in the BOF filter than in the EAF filter, as already mentioned in previous sections.
The results of the EAF filter showed that the $N$ values for the main flow path ranged between 12 and 32, whereas the $N$ values for the secondary flow path ranged between 5 and 14 . The results of the BOF filter showed that the $N$ values for the main flow path ranged between 19 and 34, whereas the $N$ values for the secondary flow path ranged between 6 and 32. It is difficult to explain these variations in $N$ values, as several physical-chemical phenomena that occur in steel slag filters may have affected the hydraulic properties of the flow paths over time. Most probably, CaO slag dissolution, hydration and carbonation, $\mathrm{P}$ precipitation, and the accumulation of suspended solids resulted in the decrease in pore size. On the one hand, the smaller pore size may have the effect of reducing preferential paths thereby improving the flow distribution throughout the filter, and leading to mean retention times closer to the value of the theoretical hydraulic retention time (Suliman et al., 2006). On the other hand, the smaller pore size may promote the reduction of the plug flow due to the higher dispersion resulting from the fluid flowing through smaller spaces (Alcocer et al., 2012). Moreover, the variation in temperature during the experiments led to fluctuating values of water viscosity, which further affected the dispersion phenomena in the filters. With the exception of week 29, the increase in $N$ values for the main flow path while the EAF filter was in operation mode suggests that the decrease in pore size reduced preferential short paths, hence improving plug-like flow distribution over time whereas the $N$ values for the main flow path in the BOF filter showed a slight tendency to decrease over time. It is likely that rather than reducing the short paths, the decrease in pore size in the BOF filter may have resulted in a slight increase in dispersion conditions over time. These differences in the internal hydrodynamics between the EAF and the BOF filters were most probably due to the differences in the physical-chemical properties of the steel slag. In fact, as shown in Fig. S1, the larger grain size distribution of the BOF slag may account for the smaller pore size in the BOF filter from the beginning of the experiments. In addition, the BOF slag was initially richer in $\mathrm{CaO}$ than the EAF slag, indicating a higher potential for hydration and carbonation of the $\mathrm{CaO}$ slag and hence the expansion of slag volume (Wang et al., 2010), which may have favored a more rapid reduction in pore size in the BOF filter than in the EAF filter.

For each experiment, the sum of the actual working volumes of the main and secondary flow paths (Table 3 ) was very close to the total actual working volumes reported in Table 1 (the differences were always less than $8 \%$ ), confirming the overall coherence of the model. In addition, the low TIC values (0.022-0.087) appear to confirm that the two flow path TIS model describes the experimental $E(t)$ very well. However, the model appears to be less efficient in describing the tracer response of the EAF filter in week 29, as shown by the relatively higher value of TIC (0.087), suggesting that the two flow path model is not sufficient for an accurate description of the experimental $E(t)$.

Table 3

Main results of the two flow path TIS model.

\begin{tabular}{|c|c|c|c|c|c|c|c|c|c|c|}
\hline \multirow{2}{*}{$\begin{array}{l}\text { Week of } \\
\text { operation }\end{array}$} & \multirow[t]{2}{*}{ Filter } & \multicolumn{4}{|l|}{ Main flow path } & \multicolumn{4}{|l|}{ Secondary flow path } & \multirow[t]{2}{*}{ TIC } \\
\hline & & $\begin{array}{l}\text { Specific volumetric flow rate } \\
(\%)\end{array}$ & $\begin{array}{l}\text { Actual working volume } \\
\left(\mathrm{m}^{3}\right)\end{array}$ & $\begin{array}{l}\tau \\
(\mathrm{h})\end{array}$ & $\mathrm{N}$ & $\begin{array}{l}\text { Specific volumetric flow rate } \\
(\%)\end{array}$ & $\begin{array}{l}\text { Actual working volume } \\
\left(\mathrm{m}^{3}\right)\end{array}$ & $\begin{array}{l}\tau \\
(\mathrm{h})\end{array}$ & & \\
\hline \multirow[t]{2}{*}{1} & EAF & 62 & 0.99 & 12.3 & 15 & 38 & 1.24 & 25.2 & 5 & 0.030 \\
\hline & BOF & 71 & 1.98 & 21.4 & 34 & 29 & 1.19 & 31.6 & 32 & 0.030 \\
\hline \multirow[t]{2}{*}{9} & EAF & 71 & 1.57 & 17.0 & 16 & 29 & 1.02 & 27.0 & 10 & 0.031 \\
\hline & BOF & 84 & 2.21 & 20.2 & 19 & 16 & 0.55 & 26.3 & 6 & 0.022 \\
\hline \multirow[t]{2}{*}{22} & EAF & 62 & 0.97 & 13.0 & 32 & 38 & 1.07 & 23.4 & 6 & 0.058 \\
\hline & BOF & 78 & 1.44 & 15.4 & 28 & 22 & 0.67 & 25.3 & 26 & 0.046 \\
\hline \multirow[t]{2}{*}{29} & EAF & 68 & 1.53 & 18.7 & 12 & 32 & 1.22 & 31.8 & 14 & 0.087 \\
\hline & BOF & 74 & 1.32 & 14.8 & 19 & 26 & 0.88 & 28.1 & 9 & 0.045 \\
\hline
\end{tabular}




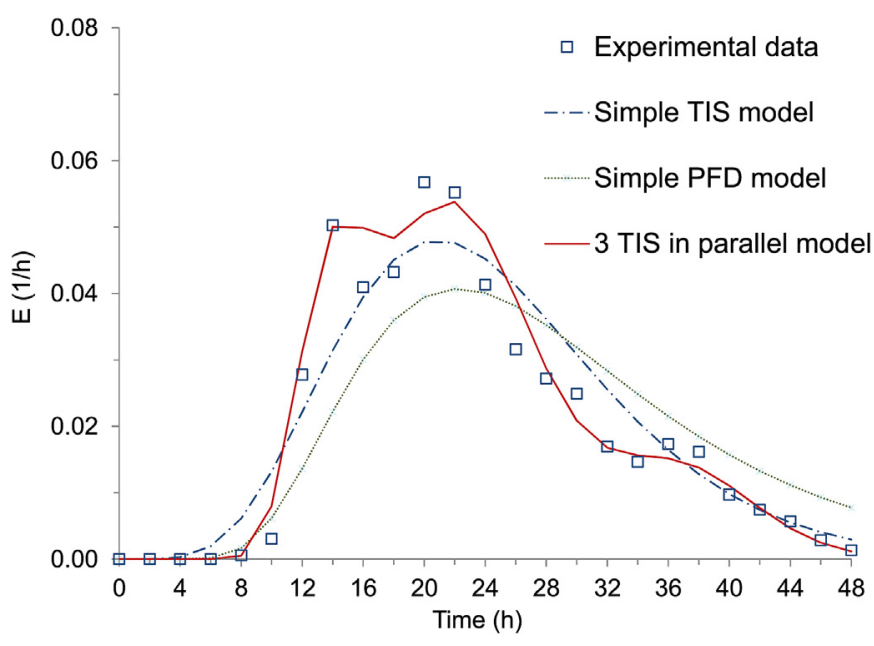

Fig. 4. Experimental and modelled $\mathrm{E}(\mathrm{t})$ for the EAF filter in week 29 of operation.

\subsubsection{Three flow path TIS model}

The results and the discussion in the previous sections already highlighted the different hydraulic behavior of the EAF filter in week 29. In Fig. 1b, the graphical analysis of the experimental $E(t)$ of the EAF filter in week 29 shows three main tracer peaks, a first peak after $12 \mathrm{~h}$, a second peak after $20 \mathrm{~h}$, and a third peak after $36 \mathrm{~h}$, suggesting the existence of three main flow paths through the filter.

For this reason, a three flow path TIS model was used to better describe the experimental $E(t)$ and to assess the internal hydrodynamics of the EAF filter in week 29. The specific volumetric rates for the first and for the third flow paths were estimated by left-toright and right-to-left symmetry of the first and of the third peak, respectively. The specific volumetric rate for the second flow path was then determined by flow balance at the inlet and at the outlet nodes.

The three flow path TIS model appears to satisfactorily describe the experimental $E(t)$ of the EAF filter in week 29, as shown in Fig. 4. The first, the second, and the third flow paths accounted for 23\%, $63 \%$, and $14 \%$ of the total inlet flow, thus leading to actual working volumes of $0.38 \mathrm{~m}^{3}, 1.67 \mathrm{~m}^{3}$, and $0.61 \mathrm{~m}^{3}$, respectively (Table 4). The sum of the actual working volumes for the first, the second, and the third flows $\left(2.66 \mathrm{~m}^{3}\right)$ was very close to the total actual working volume reported in Table $1\left(2.81 \mathrm{~m}^{3}\right)$, thus confirming the consistency of the model.

The main results of the three flow path TIS model (Table 4) appear to confirm that the internal hydrodynamics of the EAF filter in week 29 can be represented by three major flow paths with different hydraulic properties:

(i) A first faster flow path with a $\tau$ of $13.7 \mathrm{~h}$, an $N$ of 36, a specific volumetric flow rate of $23 \%$, and an actual working volume of $0.38 \mathrm{~m}^{3}$;

(ii) A second main flow path with a $\tau$ of $22.1 \mathrm{~h}$, an $N$ of 21 , a specific volumetric flow rate of $63 \%$, and an actual working volume of $1.67 \mathrm{~m}^{3}$; (iii) A third slower flow path presenting a $\tau$ of $36.1 \mathrm{~h}$, an $N$ of 67 , a specific volumetric flow rate of $14 \%$, and an actual working volume of $0.61 \mathrm{~m}^{3}$.

It is possible that $\mathrm{P}$ precipitation and the accumulation of suspended solids, followed by particle segregation during water filtration resulted in the formation of horizontal layers of different grain size along the vertical cross section of the filter, with small particles moving to the bottom and larger grains moving to the top. According to the well-known Kozeny-Carman equation, lower pore size and higher specific grain surface area probably led to lower hydraulic conductivities $\left(K_{S}\right)$ in the bottom layers than in the top layers (Chapuis and Aubertin, 2003). According to these hypotheses, the first faster flow path is most probably related to water flowing through the top layers with a higher $K_{S}$, thus leading to a shorter $\tau(13.7 \mathrm{~h})$, whereas the third slower flow path is most probably related to water flowing through the bottom layers with lower $K_{S}$, thus leading to a higher $\tau(36.1 \mathrm{~h})$. The second main flow path can thus be attributed to water flowing through the middle layers of the filter. This main flow path accounted for $63 \%$ of the total inlet flow and for $59 \%$ of the total actual working volume of the filter and also presented a mean retention time close to the value of the theoretical hydraulic retention time.

As shown in Table 4, the third slower flow path had the highest value of $N(67)$, thus indicating less mixing conditions than the first and the second flow paths. Most probably, particle segregation also had the effect of reducing preferential paths and of promoting pluglike flow distribution in the bottom layers of the filter.

On the other hand, the BOF filter showed no significant change in the shape of the experimental $E(t)$ and the two flow path TIS model efficiently describes the experimental data in week 29 (Fig. 3d). The different hydraulic behavior of the two filters in week 29 was most probably related to the different physical-chemical properties of the EAF and BOF slag used in this study, as already mentioned in previous sections, and in particular to the higher $\mathrm{CaO}$ content of the BOF slag. On the one hand, $\mathrm{CaO}$ slag dissolution may lead to particle breakage and reduce grain size. On the other hand, $\mathrm{CaO}$ slag hydration and/or carbonation could increase the volume of the slag grains. It is likely that the combined phenomena of increase/decrease in particle size had the overall effect of reducing particle segregation in the BOF filter, thus preserving the 2 main flow path behavior until week 29 .

\section{Conclusions}

The results of this study provide important information on changes in the hydraulic performances and internal hydrodynamics of steel slag filters under real dynamic operating conditions. Overall, the BOF filter indicated higher hydraulic efficiency, higher plug-like flow and lower dispersion than the EAF filter, most probably related to the higher $\mathrm{CaO}$ content, round shape and larger grain size distribution of the BOF slag. These findings confirm that the plug-like flow conditions increased with decreasing temperature, most probably because higher water viscosity at lower temperature had the effect of improving convection transport rather than dispersion phenomena. The results of the multi-flow TIS

Table 4

Main results of three flow path TIS model describing the retention time distribution curve for EAF filter in week 29 of operation (TIC $=0.064)$.

\begin{tabular}{|c|c|c|c|c|}
\hline Flow paths & Specific volumetric flow rate (\%) & Actual working volume $\left(\mathrm{m}^{3}\right)$ & $\tau(\mathrm{h})$ & $\mathrm{N}$ \\
\hline First flow path & 23 & 0.38 & 13.7 & 36 \\
\hline Second flow path & 63 & 1.67 & 22.1 & 21 \\
\hline Third flow path & 14 & 0.61 & 36.1 & 67 \\
\hline
\end{tabular}


model showed that the internal hydrodynamics of steel slag filters can be primarily described by two main flow paths: (i) a faster main flow path with higher plug flow, followed by (ii) a slower secondary flow path with higher dispersion. The results also showed that internal hydrodynamics can change over time due to the different physical-chemical phenomena that occur in the filter, including accumulation of precipitates, slag hydration and carbonation, and particle segregation, thereby leading to changes in flow transport patterns and/or in the number of main flow paths.

The results of this study demonstrate that the multi-flow path TIS model accurately describes the experimental RTD curves and provides a dynamic description of the internal hydrodynamics of the filters. In addition, the multi-flow path TIS model is easy to understand and use by non-experts, and can easily be implemented in most software dedicated to the modelling and simulation of wastewater treatment processes, with the possibility to integrate chemical, biochemical and physical-chemical kinetics.

Moreover, the systemic modelling approach developed in this study may be applied to filter units designed to treat different types of water streams such as urban, industrial and/or agricultural runoff, with a relevant impact on the field of management and control of diffuse water pollution.

\section{Acknowledgements}

This work received funding from the European Union's Research Fund for Coal and Steel (RFCS) research program under grant agreement $\mathrm{n}^{\circ}$ RFSP-CT-2009-00028 (SLASORB).

\section{Appendix A. Supplementary data}

Supplementary data related to this article can be found at https://doi.org/10.1016/j.jenvman.2017.10.040.

\section{References}

Alcocer, D.J.R., Vallejos, G.G., Champagne, P., 2012. Assessment of the plug flow and dead volume ratios in a sub-surface horizontal-flow packed-bed reactor as a representative model of a sub-surface horizontal constructed wetland. Ecol. Eng. 40, 18-26.

Barca, C., Meyer, D., Liira, M., Drissen, P., Comeau, Y., Andres, Y., Chazarenc, F., 2014. Steel slag filters to upgrade phosphorus removal in small wastewater treatment plants: removal mechanisms and performance. Ecol. Eng. 66, 214-222.

Barca, C., Troesch, S., Meyer, D., Drissen, P., Andrès, Y., Chazarenc, F., 2013. Steel slag filters to upgrade phosphorus removal in constructed wetlands: two years of field experiments. Environ. Sci. Technol. 47, 549-556.

Bonner, R., Aylward, L., Kappelmeyer, U., Sheridan, C., 2017. A comparison of three different residence time distribution modelling methodologies for horizontal subsurface flow constructed wetlands. Ecol. Eng. 99, 99-113.

Chapuis, R.P., Aubertin, M., 2003. On the use of the Kozeny-Carman equation to predict the hydraulic conductivity of soils. Can. Geotech. J. 40, 616-128.
Chazarenc, F., Merlin, G., Gonthier, Y., 2003. Hydrodynamics of horizontal subsurface flow constructed wetlands. Ecol. Eng. 21, 165-173.

Claveau-Mallet, D., Wallace, S., Comeau, Y., 2012. Model of phosphorus precipitation and crystal formation in electric arc furnace steel slag filters. Environ. Sci. Technol. 46, 1465-1470.

García, J., Chiva, J., Aguirre, P., Alvarez, E., Sierra, J., Mujeriego, R., 2004. Hydraulic behaviour of horizontal subsurface flow constructed wetlands with different aspect ratio and granular medium size. Ecol. Eng. 23, 177-187.

Headley, T.R., Kadlec, R.H., 2007. Conducting hydraulic tracer studies of constructed wetlands: a practical guide. Ecohydrol. Hydrobiol. 7, 269-282.

Hvala, N., Strmčnik, S., Šel, D., Milanič, S., Banko, B., 2005. Influence of mode validation on proper selection of process models - an industrial case study. Comput. Chem. Eng. 29, 1507-1522.

Kumar, J.L.G., Zhao, Y.Q., 2011. A review on numerous modeling approaches for effective, economical and ecological treatment wetlands. J. Environ. Manage. $92,400-406$

Lee, M.S., Drizo, A., Rizzo, D.M., Druschel, G., Hayden, N., Twohig, E., 2010. Evaluating the efficiency and temporal variation of pilot-scale constructed wetlands and steel slag phosphorus removing filters for treating dairy wastewater. Wate Res. 44, 4077-4086.

Levenspiel, O., 1999. Chemical Reaction Engineering, third ed. John Wiley \& Sons, New York.

Maloszewski, P., Wachniew, P., Czuprynski, P., 2006. Study of hydraulic parameters in heterogeneous gravel beds: constructed wetland in Nowa Slupia (Poland). J. Hydrol. 331, 630-642.

Meyer, D., Chazarenc, F., Claveau-Mallet, D., Dittmer, D., Forquet, N., Molle, P. Morvannou, A., Palfy, T., Petitjean, A., Rizzo, A., Samso Campa, R., Scholz, M. Soric, A., Langergraber, G., 2015. Modelling constructed wetlands: scopes and aims - a comparative review. Ecol. Eng. 80, 205-213.

Muñoz, P., Drizo, A., Hession, W.C., 2006. Flow patterns of dairy wastewater constructed wetlands in a cold climate. Water Res. 40, 3209-3218.

Nivala, J., Knowles, P., Dotro, G., García, J., Wallace, S., 2012. Clogging in subsurface flow treatment wetlands: measurement, modeling and management. Water Res. 46, 1625-1640.

Persson, J., Somes, N.L.G., Wong, T.H.F., 1999. Hydraulic efficiency of constructed wetlands and ponds. Water Sci. Technol. 40, 291-300.

Ríos, D.A., Véleza, A.F.T., Peña, M.R., Parra, C.A.M., 2009. Changes of flow patterns in a horizontal subsurface flow constructed wetland treating domestic wastewater in tropical regions. Ecol. Eng. 35, 274-280.

Rizzo, A., Langergraber, G., Galvão, A., Boano, F., Revelli, R., Ridolfi, L., 2014. Modelling the response of laboratory horizontal flow constructed wetlands to unsteady organic loads with HYDRUS-CWM1. Ecol. Eng. 68, 209-213.

Samsó, R., García, J., Molle, P., Forquet, N., 2016. Modelling bioclogging in variably saturated porous media and the interactions between surface/subsurface flows: application to Constructed Wetlands. J. Environ. Manage. 165, 271-279.

Shilton, A.N., Elmetri, I., Drizo, A., Pratt, S., Haverkamp, R.G., Bilby, S.C., 2006 Phosphorus removal by an "active" slag filter - a decade of full scale experience. Water Res. 40, 113-118.

Suliman, F., French, H., Haugen, L., Søvik, A., 2006. Change in flow and transport patterns in horizontal subsurface flow constructed wetlands as a result of biological growth. Ecol. Eng. 27, 124-133.

Vohla, C., Kõiv, M., Bavor, H.J., Chazarenc, F., Mander, U., 2011. Filter materials for phosphorus removal from wastewater in treatment wetlands - a review. Ecol. Eng. 37, 70-89.

Wang, G., Wang, Y., Gao, Z., 2010. Use of steel slag as a granular material: volume expansion prediction and usability criteria. J. Hazard. Mater. 184, 555-560.

Werner, T., Kadlec, R., 2000. Wetland residence time distribution modelling. Ecol Eng. 15, 77-90.

Zeng, M., Soric, A., Roche, N., 2013. Calibration of hydrodynamic behavior and biokinetics for TOC removal modeling in biofilm reactors under different hydraulic conditions. Bioresour. Technol. 144, 202-209. 